\title{
Avoidable Admissions and Repeat Admissions: What Do They Tell Us?
}

Joan Porter, Jeremy Herring, Jeanie Lacroix and Carey Levinton

eady access to primary healthcare is a desire of governments, healthcare providers and the public. One indicator that is recognized as an indirect measure of access to and quality of primary healthcare is the rate of hospitalization for ambulatory care sensitive conditions (ACSCs). An ACSC hospitalization, also known as a potentially preventable hospitalization, is one in which an individual is admitted for a condition that under most circumstances is manageable on an outpatient basis. While not all admissions for these conditions are avoidable, "timely and effective outpatient care can help to reduce the risks of hospitalization by either preventing the onset of an illness or condition, controlling an acute episodic illness or condition, or managing a chronic disease or condition" (Billings et al. 1993: 163). In this context, a disproportionately high rate may reflect problems in obtaining access to primary healthcare, differences in community- or hospital-based practice patterns or other factors. The conditions captured under this definition include angina, asthma, chronic obstructive pulmonary disease (COPD), congestive heart disease, diabetes, epilepsy and hypertension. This list is a subset of a larger selection of conditions developed by Billings et al. (1993) in a consultative process using a diagnostic framework for assessing hospital use. In 2004-2005, ACSC hospitalizations accounted for $5.1 \%$ of all acute care in-patient hospitalizations in Canada for persons less than 75 years of age at admission discharged alive, and ranged from $3.3 \%$ to $7.2 \%$ among the provinces and territories.

Figure 1. Age-standardized rates of hospitalization for ambulatory care sensitive conditions (ACSCs) among persons less than 75 years, by province/territory and Canada, 2004-2005

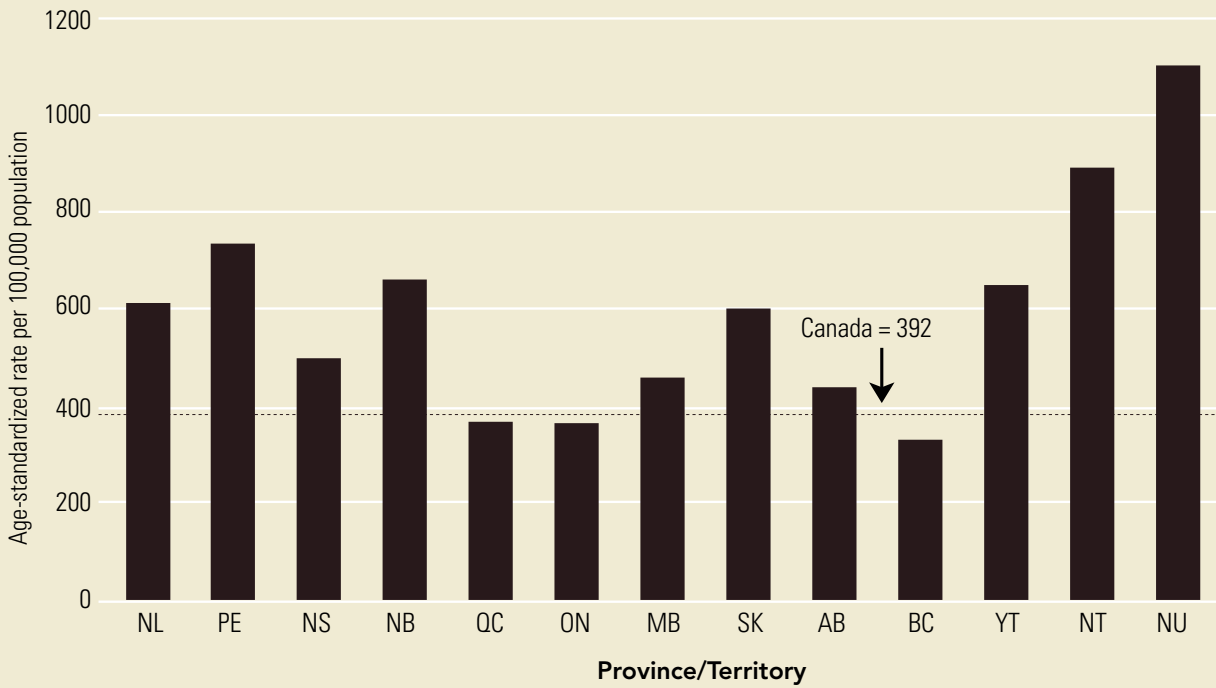

Rates are age-adjusted using a direct method of standardization based on the July 1, 1991, population. Rates are based on province/ territory of residence, not province/territory of hospitalization.

Source: Hospital Morbidity Database, $\mathrm{CIHI}$. 
ACSC hospitalization rates for those under age 75 years and discharged alive vary across the country (see Figure 1 on previous page). The rates reflect both new cases and subsequent admissions for the same or another ACSC. More males than females were found to have had an ACSC admission (55.2\%). Overall rates, as well as those for both genders, by health region, are available at www.cihi.ca/ indicators.

Among provinces and territories, between $17.1 \%$ and $24.9 \%$ of total ACSC hospitalizations within 2004-2005 were repeat admissions. In comparison, US studies have reported multiple admission rates of $14 \%$ and $19 \%$, although the conditions identified as ambulatory care sensitive are not identical to those under review here (Falik et al. 2001; Friedman and Basu 2004). In absolute terms, 15,364 individuals under the age of 75 years had at least two ACSC admissions in Canada in 2004-2005 (range 2-26 admissions).

\section{"Timely and effective outpatient} care can help to reduce the risks of hospitalization by either preventing the onset of an illness or condition, controlling an acute episodic illness or condition, or managing a chronic disease or condition"

(Billings et al. 1993: 163).

The majority of patients with more than one ACSC hospitalization returned with the same condition as the first or index admission $(84.9 \%)$, while the remaining were readmitted with a different ambulatory sensitive condition (e.g., a first admission for angina but congestive heart failure at the repeat admission). Of those who had a repeat hospitalization, the condition appearing with the greatest frequency at the index admission was COPD (Table 1). When considering frequencies for COPD and asthma combined, $52.9 \%$ of the individuals who had a repeat admission were initially admitted with a respiratory condition.
Table 1. Distribution of admissions for an ACSC and those having a repeat admission for the same or another ACSC (\%), by condition, Canada, 2004-2005

\begin{tabular}{|l|r|c|}
\hline Condition & $\begin{array}{l}\text { Total ACSC } \\
\text { Admissions* } \\
\text { by Condition } \\
(\boldsymbol{n}=\mathbf{1 2 4 , 9 7 1 )} \%\end{array}$ & $\begin{array}{l}\text { ACSC casest with a } \\
\text { Repeat Admission by } \\
\text { Condition at Index } \\
\text { Admission }(\boldsymbol{n}=\mathbf{1 5}, 364) \%\end{array}$ \\
\hline Angina & 17.6 & 11.4 \\
\hline Asthma & 17.3 & 13.8 \\
\hline Congestive heart failure & 11.8 & 14.7 \\
\hline $\begin{array}{l}\text { Chronic obstructive } \\
\text { pulmonary disease (COPD) }\end{array}$ & 29.1 & 39.1 \\
\hline Diabetes & 14.6 & 13.4 \\
\hline Epilepsy & 6.8 & 6.3 \\
\hline Hypertension & 2.8 & 1.4 \\
\hline
\end{tabular}

ACSC $=$ ambulatory care sensitive condition.

* Excludes transfers and includes repeat admissions where death occurred. An individual may be counted more than once.

tUnique individuals.

Source: Hospital Morbidity Database, $\mathrm{CIHI}$

Table 2. Median age of individuals having more than one admission and the median LOS for the index and second admission, by condition, Canada, 2004-2005

\begin{tabular}{|l|c|c|c|}
\hline Condition & $\begin{array}{l}\text { Median Age } \\
\text { (years) }\end{array}$ & $\begin{array}{l}\text { Median } \\
\text { LoS Index } \\
\text { Admission } \\
\text { (days) }\end{array}$ & $\begin{array}{l}\text { Median } \\
\text { LOS Second } \\
\text { Admission } \\
\text { (days) }\end{array}$ \\
\hline Angina & 63 & 3 & 3 \\
\hline Asthma & 16 & 2 & 2 \\
\hline Congestive heart failure & 67 & 6 & 6 \\
\hline $\begin{array}{l}\text { Chronic obstructive pulmonary } \\
\text { disease (COPD) }\end{array}$ & 67 & 5 & 6 \\
\hline Diabetes & 45 & 4 & 4 \\
\hline Epilepsy & 29 & 3 & 3 \\
\hline Hypertension & 63 & 3 & 3 \\
\hline
\end{tabular}

LOS = length of stay.

Source: Hospital Morbidity Database, $\mathrm{CIHI}$. 
Of those who returned one or more times, $42.4 \%$ were in the oldest age category (65-74 years) at the time of the index admission, a figure that is higher than the proportion among all persons, both single and repeat, who had an ACSC admission (34.3\%). To further explore the relationship between age and repeated admission, the median age of patients stratified by condition was calculated (see Table 2 on previous page). Individuals with asthma and epilepsy tended to be younger than those with other conditions. Although not shown, median age by condition for those experiencing only one admission for an ACSC was similar to the median age for those who had multiple stays, with the exception of asthma, where the one-admission group was younger (11 years), and epilepsy, where they were older (36 years). There was little variation in length of stay between index and repeat admissions, except pertaining to COPD, where the median for the second stay was one day longer.

Not all repeat hospitalizations are avoidable based on current knowledge and practice. In one study, the parents of children admitted with an ACSC, the child's primary care provider and the attending hospital physician were surveyed as to whether they believed the visit was avoidable (Flores et al. 2003). Depending on whom was asked, the proportion of stays perceived to be avoidable varied from $13 \%$ to $46 \%$.

Researchers have suggested a number of possible factors that may contribute to multiple stays for ACSCs. For example, some suggest that repeat admissions may be related to barriers to care access, particularly post-discharge follow-ups in the community (Weissman et al. 1992). Repeat hospitalization may also relate to discharge planning, coordination with primary care providers, natural history of the condition and patient compliance - factors independent of the availability of ambulatory care. Other possible explanations include non-compliance with medication schedules and post-discharge instructions, leading to deterioration of the individual's condition, a relapse requiring hospitalization and a variety of other factors. HQ

\section{References}

Billings, J., L. Zeitel, J. Lukomnik, T.S. Carey, A.E. Blank and L. Newman. 1993. "Impact of Socioeconomic Status on Hospital Use in New York City." Health Affairs Spring: 162-73.

Falik, M., J. Needleman, B.L. Wells and J. Korb. 2001. "Ambulatory Care Sensitive Hospitalizations and Emergency Visits: Experiences of Medicaid Patients Using Federally Qualified Health Centers.” Medical Care 39(6): 551-61.

Flores, G., M. Abreu, C. E. Chaisson and D. Sun. 2003. "Keeping Children Out of Hospitals: Parents' and Physicians' Perspectives on How Pediatric Hospitalizations for Ambulatory Care-Sensitive Conditions Can Be Avoided." Pediatrics 112(5): 1021-30.

Friedman, B. and J. Basu. 2004. "The Rate and Cost of Hospital Readmissions for Preventable Conditions." Medical Care Research and Review 61(2): 225-40.
Weissman, J.S., C. Gatsonis and A.M. Epstein. 1992. "Rates of Avoidable Hospitalization by Insurance Status in Massachusetts and Maryland." Journal of the American Medical Association 268(17): 2388-94.

\section{About the Authors \\ Joan Porter, MSc, is a project lead in the Health Indicators program area at $\mathrm{ClHI}$.}

Jeremy Herring is an analyst in the Health Indicators program area at $\mathrm{ClHI}$. He holds a bachelor's degree in health sciences from Brock University and is currently completing a master of science degree in population epidemiology at the University of Western Ontario, investigating the performance and attitudes toward occupational health and safety practices in surgeons and surgical residents.

Jeanie Lacroix, MPA, is a project lead in the Hospital Reports program area at $\mathrm{ClHI}$. Prior to joining $\mathrm{ClHI}$, she held various positions in health research, including with the Division of Preventive Oncology at Cancer Care Ontario and the Ontario Cancer Institute, as well as with the Northern Health Human Resources Research Unit.

Carey Levinton, MSc, Statistical Consultant for $\mathrm{ClHI}$, has over 20 years' experience working in healthcare research from both a clinical and health policy perspective. He has spent the past three years developing indicator methodology for the hospital report extensively in the area of patient satisfaction and women's health. Currently he is co-investigator on a $\mathrm{ClHI}$ grant exploring new techniques to measure gender equity in access to medical services in Canada.

\section{Ideas worth listening to.}

\section{Longwoods Radio available now at www.longwoods.com}

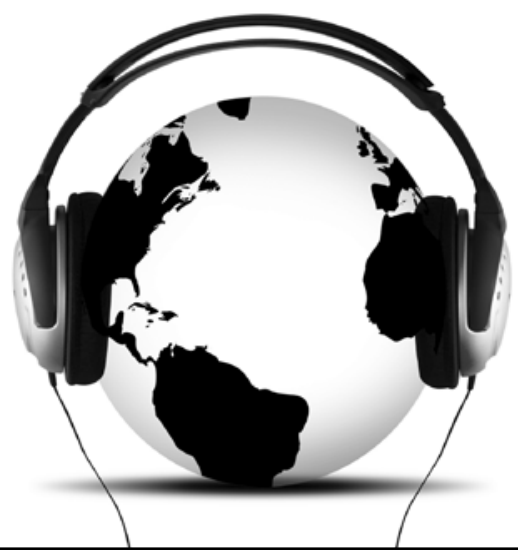

